\title{
Kadish Stage B Olfactory Neuroblastoma
}

National Cancer Institute

\section{Source}

National Cancer Institute. Kadish Stage B Olfactory Neuroblastoma. NCI Thesaurus. Code C6854.

An olfactory neuroblastoma that involves the nasal cavity and paranasal sinuses. 